FIGUEIREDO RW; OLIVEIRA AC; MAIA GA; ALVES RE; FILGUEIRAS HAC; SOUSA PHM. 2007. Qualidade do melão cantaloupe cv. Hy-Mark minimamente processado e armazenado sob refrigeração. Horticultura Brasileira 25: 114-117.

\title{
Qualidade do melão cantaloupe cv. Hy-Mark minimamente processado e armazenado sob refrigeração
}

\author{
Raimundo Wilane de Figueiredo ${ }^{1}$; Ariane Cordeiro de Oliveira ${ }^{1}$; Geraldo Arraes Maia ${ }^{1}$; Ricardo Elesbão \\ Alves $^{1}$; Heloisa Almeida Cunha Filgueiras ${ }^{2}$; Paulo Henrique Machado de Sousa ${ }^{3}$ \\ ${ }^{1}$ UFC, Depto. Tecnol. Alimentos, C. Postal 12168, 60356-000 Fortaleza-CE; ${ }^{2}$ Embrapa Agroindústria Tropical, C. Postal 3761, 60511- \\ 110 Fortaleza-CE; ${ }^{3} \mathrm{UFV}$, Depto. Tecnol. Alimentos, 36570-000 Viçosa-MG; E-mail: figueira@ufc.br; gmaia@ secrel.com.br; \\ elesbão@cnpat.embrapa.br; heloisa@cnpat.embrapa.br; phenriquemachado@gmail.com
}

\section{RESUMO}

A maioria das pesquisas em melão minimamente processado é concentrada no tipo 'cantaloupe', devido à sua importância no mercado internacional. O objetivo deste trabalho foi avaliar a qualidade do melão cantaloupe cv. Hy-Mark minimamente processado. Os frutos foram lavados e sanitizados, sendo em seguida cortados na forma de cubos, imersos em solução de $\mathrm{CaCl}_{2}$, acondicionados em embalagens flexíveis PET (tereftalato de polietileno) e armazenados a $4^{\circ} \mathrm{C}$ por 9 dias. O delineamento foi conduzido inteiramente casualizado, com três repetições. A intervalos de três dias, amostras foram coletadas e analisadas quanto a coliformes totais e fecais, e contagem de bactérias aeróbias mesófilas e bolores e leveduras, $\mathrm{pH}$, sólidos solúveis totais, acidez, vitamina $\mathrm{C}$, açúcares redutores totais, atividade de água, firmeza e análise sensorial através do atributo de aceitação global. O melão minimamente processado apresentou boa estabilidade física, físico-química, microbiológica e sensorial, estimando-se em 9 dias a vida útil deste produto a $4^{\circ} \mathrm{C}$.

Palavras-chave: Cucumis melo, pós-colheita, processamento.

\section{ABSTRACT}

Quality of cantaloupe melon cv. Hy-Mark minimally processed and refrigerated

Most of the research into minimally processed melon is focused on cantaloupe melon, due to its importance in the international market. The objective of this work was to evaluate the quality of cantaloupe melon cv. Hy-Mark, minimally processed and refrigerated. Fruits were washed, sanitized, cut and imbedded in a calcium chloride solution and packed in PET and stored at $4^{\circ} \mathrm{C}$ during 9 days. At three-day intervals samples were collected and analyzed for total and fecal coliforms, counting of aerobic mesophilic bacterias, molds and yeast, SS (soluble solids), TTA (total titrable acidity), firmness, $\mathrm{pH}$, TRS (total reducing sugar), Aw, vitamin $\mathrm{C}$, color and acceptability. The minimally processed melon showed good overall physical, pyisico-chemical, microbiological and sensorial stability during the storage period.

Keywords: Cucumis melo, postharvest, processing.

(Recebido para publicação em 13 de janeiro de 2006; aceito em 14 de abril de 2007)

\begin{abstract}
A tecnologia de processamento mí nimo objetiva satisfazer as necessidades dos consumidores de frutas e hortaliças frescas, seguindo a tendência atual de pouco tempo disponível para o preparo das refeições (Vanetti, 2000).

O melão, apesar de ainda não ser encontrado em grande escala e com freqüência no mercado na forma pré-cortada ou minimamente processada, apresenta grande potencial, pois normalmente é consumido nesta forma, sendo largamente utilizado pelo consumidor final, hotéis, lanchonetes, restaurantes e cozinhas industriais, na elaboração de refeições e sobremesas (Bastos et al., 2000).
\end{abstract}

Os produtos minimamente processados (PMP) apresentam maior atividade metabólica, com elevada taxa respiratória e de deterioração, o que diminui relativamente a sua vida de prateleira. Logo, técnicas adequadas de conservação devem ser adotadas no sentido de se estender sua vida útil, preservando- se sua qualidade (Vilas Boas et al., 2004).

A produção de melão minimamente processado deve, portanto, adotar procedimentos que assegurem a qualidade e segurança microbiológica do produto final. Dentre os procedimentos devem se destacar os processos de sanitização dos frutos e acondicionamento dos mesmos em baixas temperaturas $\left(4\right.$ a $\left.8^{\circ} \mathrm{C}\right)$. A refrigeração minimiza os processos fisiológicos naturais dos frutos, tais como a respiração e a produção de etileno que, quando acelerados, otimizam as reações metabólicas que podem anteceder o amadurecimento e senescência dos frutos (Bastos, 2004). Lamikanra \& Watson (2000) observaram que melões cantaloupe minimamente processados mantiveam a qualidade utilizando temperatura de $4^{\circ} \mathrm{C}$ durante o armazenamento. $\mathrm{O}$ controle de temperatura é uma das técnicas mais usuais e importantes para minimizar o efeito do corte em frutos e hortaliças (Brecht, 1995). Allong et al. (2000) verificaram que a temperatura de $5^{\circ} \mathrm{C}$ foi mais eficiente que $10^{\circ} \mathrm{C}$ em retardar o crescimento microbiano e preservar a qualidade sensorial de mangas minimamente processadas.

O objetivo deste trabalho foi avaliar a qualidade do melão cantaloupe minimamente processado e armazenado sob refrigeração.

\section{MATERIAL E MÉTODOS}

Melões do tipo cantaloupe (Cucumis melo), híbrido 'Hy-Mark', foram obtidos junto à CEASA de Fortaleza-CE, e levados ao laboratório da Embrapa Agroindústria Tropical em Fortaleza$\mathrm{CE}$, recepcionados e lavados inicialmente com detergente neutro, enxaguados e imediatamente imersos em tanques contendo hipoclorito de sódio $200 \mathrm{mg} \mathrm{x} \mathrm{L}^{-1}$ em tanque de aço inoxidável com mo- 
vimentação da água, durante dois minutos para desinfecção da casca. Os frutos foram armazenados a $10 \pm 1^{\circ} \mathrm{C}$ em câmara refrigerada durante aproximadamente 12 horas, objetivando a estabilização da temperatura interna do mesmo para posterior processamento.

Decorrido o tempo de armazenamento, os frutos foram cortados ao meio com o auxílio de facas em aço inox e suas sementes eliminadas com o auxílio de uma colher. Cada metade foi cortada em fatias longitudinais, e estas divididas em cubos com aproximadamente $3 \mathrm{~cm}$ de aresta. Os cubos foram submetidos à imersão em solução de $\mathrm{CaCl}_{2}$ a $1 \%$ associado a 20 ppm de hipoclorito de sódio por 20 segundos, drenados por 2 minutos para remoção de toda a água em excesso, embalados em recipientes retangulares de tereftalato de polietileno (PET) transparentes com tampa (Neoform $(\mathrm{N}-94)$ e capacidade para $200 \mathrm{~g}$ do produto, e em seguida armazenados a $4^{\circ} \mathrm{C}$ (Lamikanra $\&$ Watson, 2000) por nove dias (Arruda et al., 2003). O melão minimamente processado foi avaliado após o processamento em intervalos de três dias através de determinações físico-químicas, microbiológicas e sensoriais.

As determinações físico-químicas constaram de: $\mathrm{pH}$ utilizando phmetro $\mathrm{pH}$ Hanna Instruments, modelo HI9321, (AOAC,1992); acidez titulável (AT) em porcentagem de ácido cítrico e determinada em $1 \mathrm{~g}$ de amostra homogeneizada em $50 \mathrm{~mL}$ de água destilada com posterior titulação com solução de $\mathrm{NaOH}$ a 0,1 M, até pH 8,10 (IAL, 1985); sólidos solúveis (SS), através de leitura em refratômetro digital Atago, modelo PR101, com escala de 0 a $45^{\circ}$ Brix; ácido ascórbico (mg $100 \mathrm{~g}^{-1}$ de polpa) determinado segundo o método de Carvalho et al. (1990), que se baseia na redução do indicador 2,6diclorobenzenoindofenol (DCFI) pelo ácido ascórbico; açúcares redutores totais (ART) (Miller, 1959); firmeza, medida diretamente com texturômetro Stable micro system, modelo TA-SXT2; atividade de água, através do medidor Aqualab, modelo CX-2; e conteúdo de umidade pela evaporação direta a $70^{\circ} \mathrm{C}$, em estufa com circulação de ar, até peso constante (AOAC, 1992).

As amostras destinadas à avaliação microbiológica, no tempo zero, foram retiradas imediatamente após o corte. As aná- lises microbiológicas envolveram a contagem de microrganismos aeróbios mesófilos, de bolores e leveduras e a determinação de coliformes totais $\left(35^{\circ} \mathrm{C}\right)$ e coliformes fecais $\left(45^{\circ} \mathrm{C}\right)$, conforme Silva et al. (2001) e APHA (2001). A população de microrganismos aeróbios mesófilos foi quantificada pelo método de semeadura em profundidade, em ágar, para contagem padrão (Merck, EUA). As placas foram incubadas a $35^{\circ} \mathrm{C}$, por $24-48$ horas, e o resultado expresso em unidades formadoras de colônia por grama do produto $\left(\mathrm{UFC}^{\mathrm{g}} \mathrm{g}^{-1}\right)$. A população de bolores e leveduras foi determinada pelo método de semeadura em superfície em ágar batata dextrosado acidificado (Merck, EUA). As placas foram incubadas (invertidas) a 21$22^{\circ} \mathrm{C}$ por 3-5 dias. O resultado foi expresso em unidades formadoras de colônia por grama do produto (UFC. $\mathrm{g}^{-1}$ ).

A determinação do número mais provável de coliformes totais (NMP $\mathrm{x}$ $\mathrm{g}^{-1}$ ) foi realizada através de teste presuntivo em caldo lauril sulfato triptose (Difco, EUA), incubado a $35^{\circ} \mathrm{C}$ por 24-48 horas, e de teste confirmativo em caldo bile verde brilhante, a $35^{\circ} \mathrm{C}$ por 24-48 horas. Em seguida, foi determinado o número mais provável de coliformes fecais em caldo Escherichia coli (EC, Difco, EUA), incubado a $45,5^{\circ} \mathrm{C}$ por 24 horas.

A avaliação sensorial envolveu 30 julgadores não-treinados em teste laboratorial (Stone \& Sidel, 1993) através de teste de aceitação global. Utilizou-se escala hedônica de 9 pontos, ancorada nos extremos em "gostei muitíssimo" (9) e "desgostei muitíssimo" (1) conforme Monteiro (1984).

Os experimentos foram realizados em delineamento inteiramente casualizado. Foram realizadas três repetições, sendo cada uma representada por uma embalagem com 20 cubos de melão. Os dados foram avaliados através do teste $\mathrm{F}$ na análise de variância ao nível de 5\% de probabilidade e posterior estudo de regressão polinomial, sendo verificada a significância de cada termo da equação através do teste t, utilizando-se o programa estatístico SAEG (1999).

\section{RESULTADOS E DISCUSSÃO}

Dentre as características físicoquimicas do melão minimamente processado avaliadas, somente a AT dife- riu significativamente ao nível de 5\% de significância em função do tempo de armazenamento (Figura 1).

$\mathrm{O}$ valor médio do $\mathrm{pH}$ do melão durante o tempo de armazenamento foi de 6,4, concordando com Larson \& Johnson (1999) que obtiveram o valor inicial de $\mathrm{pH}$ de 6,4 para melão Cantaloupe minimamente processado a $7 \mathrm{C}$, indicando que o produto não sofreu nenhum tipo de fermentação em virtude de uma possível contaminação microbiológica.

Os valores obtidos para AT (Figura 1) apresentaram diferença significativa $(\mathrm{p} \leq 0,05)$ no decorrer do tempo de armazenamento. Observou-se que o produto sofreu uma queda no teor ácido cítrico variando inicialmente de 0,067 a $0,050 \%$ a partir do $6^{\circ}$ dia de armazenamento, concordando com Wills et al. (1990) que confirmam a degradação de ácido cítrico durante a senescência, indicando o uso dos ácidos orgânicos como fonte de energia ao longo do período de armazenamento.

Não foram observadas variações nos teores de sólidos solúveis ( $\left.8{ }^{\circ} \mathrm{Brix}\right)$ em relação ao tempo de armazenamento. Isto se deve à uniformidade do estádio de maturação dos frutos processados, já que não há aumento de sólidos solúveis depois da colheita (Filgueiras et al., 2000).

Segundo Arruda et al. (2003), a estabilidade dos teores de sólidos solúveis e do $\mathrm{pH}$, provavelmente, também está associada a baixas temperaturas, não observando diferença para os valores de sólidos solúveis totais e $\mathrm{pH}$ em melão do tipo rendilhado cv. Bônus II durante nove dias a $3^{\circ} \mathrm{C}$. Lamikanra et al. (2000) também não observaram mudanças significativas nos teores de sólidos solúveis e $\mathrm{pH}$ de melões cantaloupe minimamente processados e armazenados a $4^{\circ} \mathrm{C}$ por 14 dias.

Observou-se uma leve variação para os teores de ART (3,0 a 3,5\%) ao longo do tempo de armazenamento, reafirmando a uniformidade do estádio de maturação dos frutos utilizados no processo, tendo como indicador de colheita os sólidos solúveis em aproximadamente $8^{\circ}$ Brix (Filgueiras et al., 2000).

$\mathrm{O}$ teor de ácido ascórbico variou entre 1,7 e 1,0 mg x $100 \mathrm{~g}^{-1}$ de amostra durante os nove dias de armazenamento, correspondendo a uma redução de 41,2\% no teor deste ácido desde o iní- 

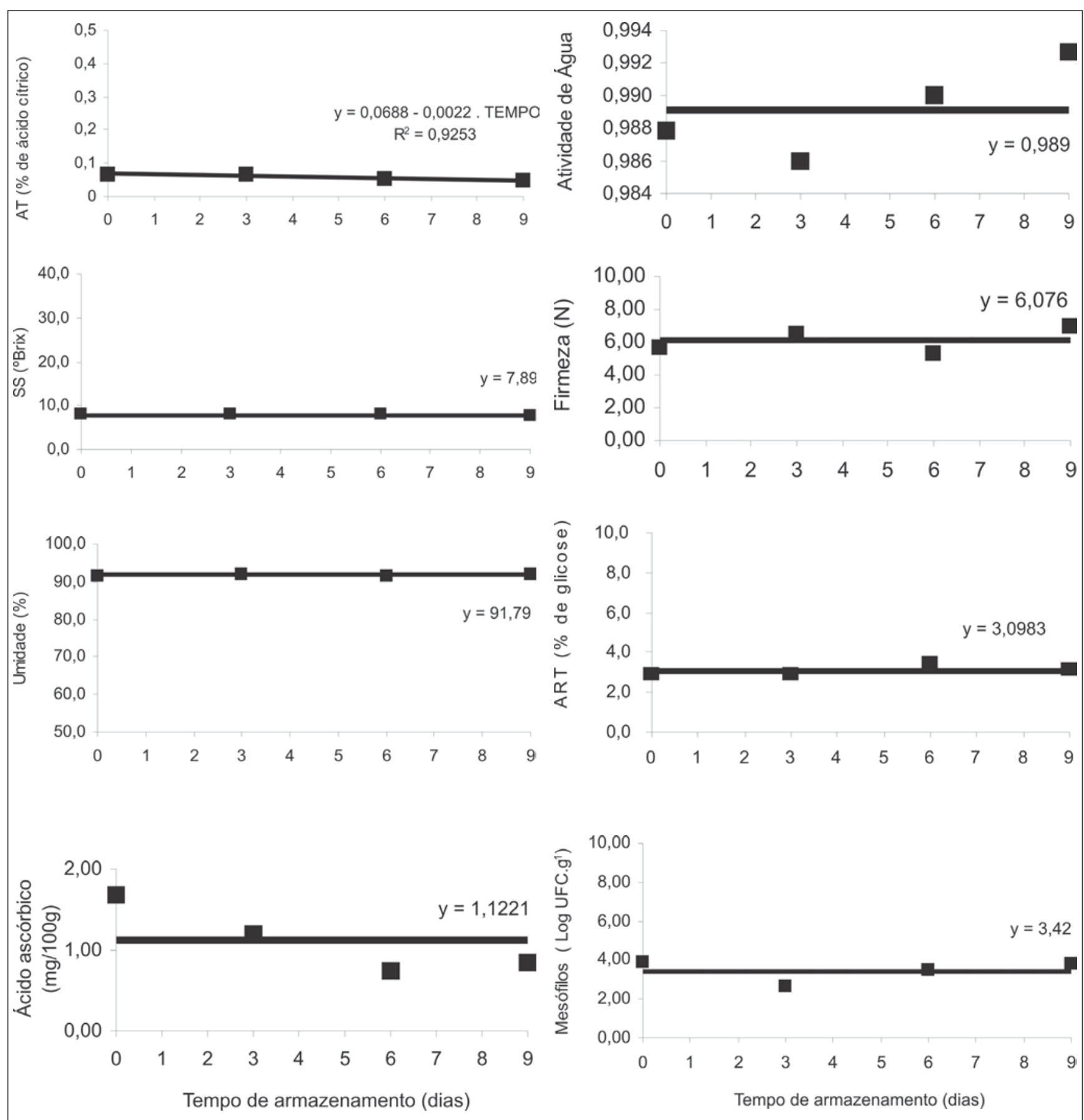

Figura 1. Acidez titulável (AT), sólidos solúveis (SS), umidade, ácido ascórbico, atividade de água, firmeza, açúcares redutores totais (ART) e contagem de mesófilos em melões cantaloupe minimamente processados armazenados a $4^{\circ} \mathrm{C} \pm 1{ }^{\circ} \mathrm{C}$ durante 9 dias (Titratable acidity (AT), soluble solids (SS), umidity, ascorbic acid, water activity, firmness, total reductable sugars (ART) and counting of mesophyls on cantaloupe melon fruits, minimally processed and stored under $4{ }^{\circ} \mathrm{C} \pm 1^{\circ} \mathrm{C}$ during 9 days). Fortaleza, UFC, 2005.

cio do experimento. Os frutos já apresentavam teores consideravelmente baixos de ácido ascórbico provavelmente pelo fato de terem sido obtidos no mercado atacadista de Fortaleza e submetidos a mau acondicionamento, armazenamento inadequado e altas temperaturas, fatores que desencadeiam rá- pida oxidação do ácido ascórbico (Barth et al., 1990).

Não foi observada diferença significativa ( $p>0,05)$ para a firmeza do melão minimamente processado (Figura 1) em função do tempo de armazenamento. Já Arruda et al. (2003) verificaram uma redução significativa na firmeza da pol- pa em nove dias de armazenamento de melão rendilhados híbrido bônus II minimamente processado e armazenados a $3^{\circ} \mathrm{C}, 6^{\circ} \mathrm{C}$ e $9^{\circ} \mathrm{C}$. Portela \& Cantwell (1998) também verificaram decréscimo na firmeza dos pedaços de melão cantaloupe armazenados a $5^{\circ} \mathrm{C}$, por 12 dias. Portela et al. (1997) citam a tem- 
peratura como fator mais importante para conservação de melão minimamente processado. Estes autores observaram que pedaços de melões mantidos a $5^{\circ} \mathrm{C}$, por 9 dias, apresentaram maior firmeza do que a $10^{\circ} \mathrm{C}$.

Durante o tempo de armazenamento foi observado que os níveis de atividade de água do produto se mantiveram constantes, em torno de 0,99 , estabelecendo uma relação direta com a estabilidade da umidade do produto (Figura 1). $\mathrm{O}$ valor da umidade foi constante $(91,8 \%)$ constatando-se que a embalagem PET atingiu as expectativas.

O número de bactérias aeróbias mesófilas (Figura 1) oscilou de 4,3 x 10²a $7,0 \times 10^{3}$ UFC. $^{-1}$ durante o período de 9 dias de armazenamento. De acordo com Mões-Oliveira et al. (2000), a exposição de superfícies cortadas, alto conteúdo de umidade e a sua manipulação podem aumentar e alterar a microbiota, comprometendo o consumo do produto minimamente processado. As determinações de coliformes totais (coliformes a $35^{\circ} \mathrm{C}$ ), coliformes fecais (coliformes a $45^{\circ} \mathrm{C}$ ), e $E$. coli apresentaram valores inferiores a 3 $\mathrm{NMP} / \mathrm{g}$. Observou-se durante o experimento que a contagem de fungos filamentosos e leveduras não apresentou variações significativas no produto final, mantendo-se constante em valores menores que 100 UFC x g g $^{-1}$. Portanto, os produtos encontraram-se dentro dos padrões de consumo de frutas e hortaliças durante o período de 9 dias, indicando que as etapas do processo foram realizadas em condições higiênicosanitárias satisfatórias (Silva et al., 2001).

Pinheiro et al. (2005), avaliando amostras comerciais de melão japonês minimamente processados, encontraram coliformes totais variando entre 4,0 x $10^{2}$ NMP.g ${ }^{-1}$ e 2,4 x $10^{6}$ NMP.g $^{-1}$, coliformes fecais de $<3$ NMP.g $^{-1}$ a $1,5 \times 10^{6}$ NMP.g${ }^{1}$ e fungos filamentosos e leveduras que variaram de 2,6 x 10 $0^{3} \mathrm{UFC}$. $\mathrm{g}^{-1}$ a $1,8 \times 10^{6}$ UFC. $\mathrm{g}^{-1}$. A presença de fungos em número elevado é indesejável, pois estes são capazes de produzir grande variedade de enzimas, as quais provocam a deterioração de frutos. Além disso, muitos bolores podem produzir metabólicos tóxicos quando estão se desenvolvendo nos alimentos (Pinheiro et al., 2005).

$\mathrm{Na}$ avaliação sensorial obtiveram-se valores médios para aceitação global variando entre sete e oito na escala hedônica, correspondendo aos termos hedônicos "gostei moderadamente" e "gostei muito", respectivamente, indicando uma boa aceitação por parte dos provadores.

Em um trabalho com cubos de melão cantaloupe minimamente processados e armazenados a $4^{\circ} \mathrm{C}$, durante 11 dias de armazenamento, O'ConnorShaw et al. (1994) observaram coloração opaca, sem brilho e com evidência de perda de água, cujos tecidos da polpa mostraram-se sensivelmente murchos, com comprometimento direto das condições para consumo.

Com base nos resultados obtidos, conclui-se que o melão minimamente processado apresentou boa estabilidade físico-química, microbiológica e sensorial, sendo a temperatura de $4^{\circ} \mathrm{C}$ satisfatória para armazenamento do produto por um período de nove dias.

\section{REFERÊNCIAS}

APHA (AMERICAN PUBLIC HEALTH ASSOCIATION).DOWNES. 2001. Compendium of methods for the microbiological examination offoods.1 ed., Washington, DC. 676p.

ARRUDA MC; JACOMINO AP; KLUGE RA AZZOLINI M. 2003. Temperatura de armazenamento e tipo de corte para melão minimamente processado. Revista Brasileira de Fruticultura 25: 74-76.

ASSOCIATION OF OFFICIAL ANALITICAL CHEMISTRY (AOAC). 1992. Official Methods of Analysis of the Association of Official Analytical Chemistry. 12 ed. Washington. $1115 \mathrm{p}$.

BARTH MM; PERRY AK; SCHMIDT SJ; KLEIN BP. 1990. Misting effects on ascorbic acid retention in brocoli during cabinet display. Journal of Food Science 55: 1187-1188.

BASTOS MSR. 2004. Processamento mínimo de melão Cantaloupe 'Hy-Mark': qualidade e segurança. 155 f. (Tese Doutorado) - Universidade Federal de Viçosa, MG.

BASTOS MSR; SOUSA FILHO MSM; ALVES RE; FILGUEIRAS HAC; BORGES MF. 2000. Processamento mínimo de melão e abacaxi. In: II Encontro de Processamento Mínimo de Frutas e Hortaliças, 2000, Viçosa, MG. Palestra..., Viçosa, MG, ed. UFV, p.89-94.

CARVALHOCRL; MANTOVANIDMB; CARVALHO PRN; MORAES RMM. 1990. Análises químicas de alimentos: manual técnico. Campinas: Instituto de Tecnologia de Alimentos. 121p.

FILGUEIRAS, HAC; MENEZES JB; ALVES RE; COSTA FV; PEREIRA LSE; GOMES JÚNIOR J. 2000. Colheita e Manuseio Póscolheita. In: Melão. Pós-Colheital Fortaleza, CE: Embrapa Agroindústria Tropical. Brasília: Embrapa Comunicação p/ Transferência de Tecnologia. 43p. (Frutas do Brasil, 10).

INSTITUTO ADOLFO LUTZ. 1985. Normas Analíticas, Métodos Químicos e Físicos para Análise de Alimentos. 3 ed. São Paulo, v.1, 533p.
LAMIKANRA O; CHEN JC; BANKS D. 2000. Biochemical and microbial changes during the storage of minimally processes cantaloupe. Journal of Agricultural and Food Chemistry 48: 5955-5961.

LAMIKANRAO; WATSON MA. 2000. Cantaloupe melon peroxidase: characterization and effects of additives on activity. Nahrung 24: 168-172.

LARSON AE; JOHNSON EA. 1999. Evaluation of botulinal toxin production in packaged fresh-cut cantaloupe and honeydew melons. Journal of Food Protection 62: 948-952.

MILLER GL. 1959. Use of dinitrosalicycle acid reagent for determination of reducing sugars. Analytical Chemistry 31: 226-248.

MÕES-OLIVEIRA EC; LIMA LCO; JUNQUEIRA ADA. 2000. Caracterização microbiológica do mamão (Carica papaya) minimamente processado: resultados preliminares. In: II Encontro nacional sobre processamento mínimo de frutas e hortaliças, 2000,Viçosa, MG. Resumos. Ed. Universidade de Viçosa, p. 12.

MONTEIRO CBL. 1984. Técnicas de avaliação sensorial. 2 ed. Curitiba: UFPR/CEPPA, $101 \mathrm{p}$.

O'CONNOR-SHAW RE; ROBERTS R; FORD AL; NOTTINGHAM SM. 1994. Shelf life of minimally processed honeydew, kiwifruit, papaya, pineapple and cantaloupe. Journal of Food Science 59, 1202p.

PINHEIRO NMS; FIGUEIREDO EAT; FIGUEIREDO RW; MAIA GA; SOUZA PHM 2005. Avaliação da qualidade microbiológica de frutos minimamente processados comercializados em supermercados de fortaleza. Revista Brasileira de Fruticultura 27: 153-156.

PORTELA S; NIE X; SUSLOW T; CANTWELL M; GORNY JR. 1997. Changes in sensory quality and fermentative volatile concentrations of minimally processed cantaloupe stored in controlled atmospheres. In: INTERNATIONAL CONTROLLED RESEARCH CONFERENCE, 7., 1997, Davis. Proceedings. Davis: University of California. p.123-129.

PORTELA SI; CANTWELL MI. 1998. Quality changes of minimally processed honeydew melons stored in air or controlled atmosphere. Postharvest Biology and Technology 14: 351-357.

SAEG (Sistema para análises estatísticas e genéticas). 1999. Viçosa, MG: UFV. Versão 8.1.

SILVA N; JUNQUEIRA VCA; SILVEIRA NFA. 2001. Manual de Métodos de Análise Microbiológica de Alimentos. $2^{\mathrm{a}}$ ed. São Paulo: Livraria Varela. 229p.

STONE H; SIDEL JL. 1993. Sensory Evaluation Practices, New York: Academic Press, 338p.

VANETTI MCD. 2000. Controle microbiológico e higiene no processamento mínimo. In: ENCONTRO NACIONAL SOBRE PROCESSAMENTO MÍNIMO DE FRUTAS E HORTALIÇAS, 2, 2000, Viçosa. Palestras... Viçosa: UFV. p.44-52.

VILAS BOAS BM; PRADO MET; VILAS BOAS EVB; NUNES EE; ARAÚJO FMMC; CHITARRA EB. 2004. Qualidade pós-colheita de melão 'Orange Flesh' minimamente processado armazenado sob refrigeração e atmosfera modificada. Revista Brasileira de Fruticultura 26: 424-427.

WILLS RBH; McGLASSON WB; GRAHAN D; LEE TH; HALL EG. 1990. Postharvest - An introduction to the physiology and handling of fruits and vegetables. Springer US; Auflage, 3rd ed. 174p. 